\title{
Knot detection in computed tomography images of partially dried jack pine (Pinus banksiana Lamb.) and white spruce (Picea glauca (Moench) Voss) logs from a Nelder type plantation
}

This is an author's post-print version of an article published in the Canadian Journal of Forest Research. The final version of the article is available at http://www.nrcresearchpress.com/doi/pdf/10.1139/cjfr-2016-0423

Fredriksson, Magnus

Luleå University of Technology, Skellefteå Campus

SE-931 87, Skellefteå, Sweden

E-mail: magnus.1.fredriksson@ltu.se

Cool, Julie

University of British Columbia

Forest Sciences Centre 4024

2424, Main Mall

Vancouver, BC V6T 1Z4, Canada

E-mail: julie.cool@ubc.ca

Duchesne, Isabelle

Natural Resources Canada

Canadian Wood Fibre Centre

1055 du P.E.P.S., C.P. 10380, Stn Sainte-Foy

Québec, QC, G1V 4C7 Canada.

E-mail: isabelle.duchesne@canada.ca

Belley, Denis

Ministère des Forêts, de la Faune et des Parcs

5700, 4e Avenue Ouest

Québec, QC, G1H 6R1 Canada

E-mail : denis.belley@mffp.gouv.qc.ca

Corresponding author:

Magnus Fredriksson

Luleå University of Technology, Skellefteå Campus

SE-931 87, Skellefteå, Sweden

Telephone: $\quad+46(0) 910585708$

Fax: +46(0)910 585399

E-mail: magnus.1.fredriksson@ltu.se 


\section{Abstract}

2 X-ray computed tomography (CT) of logs means possibilities for optimizing breakdown in

3 sawmills. This depends on accurate detection of knots to assess internal quality. However, as

4 logs are stored they dry to some extent, and this drying affects the density variation in the log,

5 and therefore the X-ray images. For this reason it is hypothetically difficult to detect log

6 features in partially dried logs using X-ray CT. This paper investigates the effect of improper

7 heartwood-sapwood border detection, possibly due to partial drying, on knot detection in jack

8 pine (Pinus banksiana Lamb.) and white spruce (Picea glauca (Moench) Voss) logs from New

9 Brunswick, Canada. An automatic knot detection algorithm was compared to manual reference knot measurements, and the results showed that knot detection was affected by detected heartwood shape. It was also shown that logs can be sorted into two groups based on

12 how well the heartwood-sapwood border is detected, to separate logs with a high knot detection rate from those with a low detection rate. In that way, a decision can be made whether or not to trust the knot models obtained from CT scanning. This can potentially aid both sawmills and researchers working with log models based on CT. 


\section{Introduction}

As industrial X-ray computed tomography (CT) scanners were introduced to the market a few years ago (Guidiceandrea 2011), new opportunities for optimizing production in sawmills have arisen. Since CT scanning uses X-rays, internal log features with density variation can be distinguished. Examples of such features are heartwood-sapwood (Longuetaud et al. 2007), knots (Bhandarkar et al. 1999, Andreu and Rinnhofer 2003, Longuetaud et al. 2012, Johansson et al. 2013), checks (Bhandarkar et al. 1999, Andreu and Rinnhofer 2003, Wehrhausen et al. 2012), decay (Schmoldt et al. 1996) and resin pockets (Oja and Temnerud 1999). Recent studies on automatic knot detection in CT images of logs include Krähenbühl et al. (2014) and Roussel et al. (2014), who developed two algorithms that are promising in terms of detecting knots in sapwood.

Once these log features are detected, sawmill production can be controlled in various ways to make sure that the value of the resulting sawn timber is maximized with regard to these internal features. For instance, Rinnhofer et al. (2003) tested a semi-automatic optimization method using CT scanning of spruce and larch logs, indicating a possible yield increase of 6 9 \% for spruce, but zero for larch. Lundahl and Grönlund (2010) varied rotation, offset and skew of Scots pine (Pinus sylvestris L.) log models derived from CT scanning, choosing the optimal position for volume yield. This increased volume yield by $4.5 \%$ compared to sawing logs horns down and centered. In Berglund et al. (2013), it is shown that choosing an optimal rotational position of a Scots pine and Norway spruce (Picea abies (L.) Karst.) logs based on CT data can improve value yield by about $13 \%$. Stängle et al. (2015) showed that value and volume yield of beech (Fagus sylvatica L.) logs can be increased by up to $24 \%$ when optimizing log rotation based on CT data, compared to an average value from 12 different rotations. 
However, some peculiarities of the sawmill industry make scanning and detection of density related features in logs difficult. For instance, the moisture content of the log will affect scanning results since wood that contains water have a higher density than wood which is dry (Lindgren 1991). Logs that are stored for a long time, e.g. in a log yard, can dry to a varying extent depending on the bark retention/damage on the log and the surrounding environment (Droessler et al. 1986, Defo and Brunette 2006). Since the exact moisture distribution in a log is usually unknown prior to scanning, detection algorithms need to be prepared to handle variations in moisture content within logs.

In particular, the knot detection algorithm described by Johansson et al. (2013) depends on an accurate detection of pith, sapwood-heartwood border and outer shape of the log. In a fully dried log, the sapwood density will be very close to that of the heartwood, thus making distinction between the two nearly impossible. If a log is partially dried, the sapwoodheartwood border will be possible to discern in some places but not in others, since "dry pockets” are formed that makes separation between heartwood and sapwood difficult in certain regions of the log. Another complication is large knots, which can have an adverse effect on the detection of sapwood-heartwood border despite measures taken within the detection algorithm to avoid it. The detection algorithm is further detailed in Baumgartner et al. (2010). One example of a poorly detected sapwood-heartwood border is shown in Figure 1. An irregular heartwood shape might lead to irregularly shaped detected knots if the Johansson et al. (2013) algorithm is used.

Furthermore, when these problems arise, there is usually no way for the sawmill to know whether or not logs have drying problems. This could be solved by using the data from CT scans of the logs, since this data contain information on log density and therefore, to some extent, moisture content in different regions of the logs. 
Given the hypothetical difficulties of detecting knots properly in partially dried out logs or with large knots, the objective of this study was to apply the knot detection algorithm developed by Johansson et al. (2013) on partially dried logs of jack pine (Pinus banksiana Lamb.) and white spruce (Picea glauca (Moench) Voss), to evaluate how the drying affects the detection results. A secondary objective was to classify the logs with high and low knot detection rates, respectively, in a way that can be measured by CT scanning. In this way, when scanning partially dried logs for knots, it can be known a priori what the chances are that the knot detection will be successful. This classification was based on the shape regularity of the detected sapwood-heartwood border, which hypothetically will be affected both by dry pockets and large knots.

\section{Materials and Methods}

\section{Tree Selection}

Trees were harvested from a Nelder Spacing Experiment type 1a design (Nelder 1962) established in 1977 near Woodstock, New Brunswick, Canada $\left(46.16^{\circ} \mathrm{N}, 67.58^{\circ} \mathrm{W}\right)$. The circular plot was divided into two sections, where one was dedicated to jack pine and the other to white spruce. Stand densities varied from about 600 stems/ha on the periphery of the plot to 12000 stems/ha in its centre. No silvicultural treatments (e.g. thinning) were performed after plantation establishment.

A total of 53 trees were selected for this study, 22 jack pine and 31 white spruce. These were 32 years old at the time of harvest in December 2009. During harvesting, dead trees or trees with defects such as forks were removed from the sample. After felling, stems were topped at a $7 \mathrm{~cm}$ diameter to consider only merchantable volume and transported to Quebec where they were stored outdoors for about 5 months. Stems were thereafter bucked into $2.5 \mathrm{~m}$-long logs in May 2010. Overall, 173 logs were produced in this way and sent to Institut national de la 
recherche scientifique (INRS) in Quebec City for CT scanning, which was performed in JuneJuly 2010. The logs were stored outdoors between operations.

\section{X-ray scanning and data preparation}

X-ray CT images were obtained for all stems. Scans were performed every millimeter along the logs with a Siemens Somatom Sensation CT scanner. The physical pixel size for each cross-section was $0.605 \mathrm{~mm} /$ pixel. The pixel resolution was $512 \times 512$.

Forty of these logs were selected for this study, 20 of each species. The selection was made to maximize the range of tree and log characteristics, such as diameter at breast height (DBH), maximum branch diameter, height of the green crown and log type (butt-, middle- and top logs). These features are summarized in Table 1. Thirteen butt logs, fourteen middle logs and thirteen top logs were chosen. These were taken from 13 jack pine trees and 14 white spruce trees, so in some cases several logs came from the same tree.

\section{Knot detection algorithm}

A knot detection algorithm developed by Johansson et al. (2013) was applied to the CT stacks of all logs of this study. Prerequisites for the algorithm are a detected pith position, an outer shape border and a sapwood-heartwood border. Pith detection was done by using Hough transforms as described by Longuetaud et al. (2004). Sapwood-heartwood and outer shape border were found using a series of filters applied on polar images of the logs' CT images, where the polar images had their origin at the pith. This was basically the algorithm described by Longuetaud et al. (2007), with the modifications described by Baumgartner et al. (2010). Both borders were described by polar coordinates for each CT cross-section, with 360 points for each slice, i.e. one radius at every angular degree.

In short, the algorithm works by creating concentric surfaces (CS's) that extend outwards from the pith of the log. CS's are close to cylindrical shells cut out at a certain radius in the 
CT stacks, following either the heartwood shape or the outer shape of the log. Ten CS's are used for each log, of which at least five need to be from the heartwood since knots are more easily found in the heartwood (Pietikäinen 1996, Tong et al. 2013). In all heartwood CS’s, knot objects are found using a thresholding operation, after which ellipses are fit to the objects if these are of a reasonable size and orientation. The knot ellipses are then matched together to form knots. The knots in the heartwood are then extrapolated to trace knots in the sapwood, by finding regions of interest in the sapwood CS's and using morphological dilation to find the position and size of the knot within that region. After this, the knot end positions are calculated, and the dead knot border is set to the point where the knot reaches its maximum diameter. Finally, a parameterized knot model is created using regression models for the size and position of each knot.

The parameters used in the algorithm were originally set to achieve a high detection rate and low amount of false detections in Scots pine (Pinus sylvestris L.) and Norway spruce (Picea abies L. Karst) logs. In this study, we used the same parameters as in the Johansson et al. (2013) study, where further details can be found. For instance, we used 10 CS's in total, the size of the median filter used in each CS was $510 \times 510 \mathrm{~mm}$, and so on.

\section{Reference measurements of knots}

Reference measurements were made manually in the CT images to enable validation of knot geometry including size, position and end point. The measurements were done by drawing ellipses around knots in log CS’s in the same manner as in Johansson et al. (2013). Ellipses for each non-occluded knot were drawn at radii at $10 \%, 20 \%, \ldots, 90 \%$ of the log radius. This yielded a total of nine ellipses per knot from the pith to the outer surface of the log. For occluded knots, ellipses were drawn to the knot end point, the position of which was marked in order to validate detection of the knot end. For the jack pine logs, 778 knots were measured, while 955 knots were measured for white spruce. Not all knots were measured, but 
140 at least half of the knot population in each log was included. The number of knots per log

141 depended on the knottiness of the log but varied between 26 and 131. The knots were chosen

142 in a way that varied size, position and type as much as possible. Since the manual

143 measurements were made in CT images and not on actual wood surfaces, there is a

144 measurement error present. This error is even higher in the sapwood region, since the contrast

145 between knot and regular wood density is lower than in the heartwood. The manually drawn

146 ellipses were parameterized using the same model as the automatically measured knots for

147 comparison. 


\section{Classification of log heartwood shape}

For all logs, the detected sapwood thickness was calculated by subtracting the heartwoodsapwood border radius from the outer shape radius, expressed in millimeters. In each CT cross-section, the standard deviation of sapwood thickness was then calculated as a measure of dispersion. A high standard deviation indicates an irregularly shaped detected heartwood. This was verified by visual inspection of the CT stacks, to make sure that most of the variation in heartwood shape was due to dry pockets, and not ovality etc. Finally, to get a measure that could be used for the entire log, the average standard deviation over all crosssections in the log was calculated. This was done for all logs of the study.

Logs were grouped in two categories based on this measurement. The cut-off was chosen with the aim of sorting them into groups of approximately the same size, one group with a lower standard deviation and one group with higher. The group with the lower standard deviation was named the Regular Heartwood (RH) group, while the other group was named the Irregular Heartwood (IH) group. The cut-off was done at a sapwood thickness standard deviation of $6 \mathrm{~mm}$. Twenty-one logs were below this threshold and were assigned to the $\mathrm{RH}$ group, while 19 were above and were thus assigned to the IH group.

\section{Results}

In Figure 2 the knot detection rate depending on the standard deviation of the detected sapwood thickness is presented.

Figure 2, shows a decreased knot detection rate with an increased standard deviation, but not with any large significance. The coefficient of determination $\left(\mathrm{R}^{2}\right)$ value is rather low, 0.19. For the linear regression model, the p-values for the intercept and the slope were $2.4 \times 10^{-10}$ and 0.0044, respectively, indicating that the model terms are significant at the $99 \%$ level, despite the low $\mathrm{R}^{2}$. However, this is not enough to draw any definite conclusions, especially 
173 given the small sample used. Using $p=0.01$ as a test for significance is not necessarily enough according to Colquhoun (2014). The decrease in detection rate should thus be considered very carefully.

The knot detection rates and rate of false detections are presented in Table 2, for the $\mathrm{RH}$ and IH groups and also separated by species. Overall, 937 knots were detected in the RH group and 796 in the IH group.

A two-proportion z-test was done, with $p_{1}=$ detection rate of the $\mathrm{RH}$ group, and $p_{2}=$ detection rate of the IH group. Choosing a z-test was justified by the large sample size of both groups. Using the null hypothesis that $p_{1}=p_{2}$ gives a $z$ of $10.2\left(n_{1}=955, n_{2}=778\right)$ which means the null hypothesis can be rejected at the 99.9\% level, i.e. the two detection rates are probably not similar.

Most of the false positives that were found, were knots that were detected as two knots. These knots usually had a low density centre, which split the knot in two high density regions as shown in Figure 3.

The detection accuracy of knot diameter, position and end point is presented in Table 3. Here, the logs are not separated by species, only based on their RH and IH groups. A negative mean error means that the algorithm underestimates the knot feature. Diameter validation was done for three different size classes: small $(<10 \mathrm{~mm})$, medium $(10-20 \mathrm{~mm})$ and big knots $(>20$ $\mathrm{mm})$.

\section{Discussion}

For almost all features presented in Table 3, the group with more regular heartwood (RH) outperformed the other (IH) group. In comparison to the results presented by Johansson et al. (2013) for Scots pine and Norway spruce, the results presented here are similar, especially for the RH group of logs, with an RMSE for knot diameter of around $5 \mathrm{~mm}$. These results 
confirm that partially dried logs could induce knot detection problems for the Johansson et al. (2013) algorithm if they are characterized by an irregular heartwood area. The knot detection algorithm works with concentric surfaces based on the sapwood-heartwood border, and a poorly detected border results in distortions of the knot shape throughout the concentric surfaces that means knots are not recognized. This could be the effect both of partial drying and possibly large knot clusters, but the underlying factors are less relevant since we used the detected heartwood shape as an indicator.

The knot detection is in some cases easier in dried sapwood (Johansson et al. 2013), so full drying of logs is a smaller problem than partial drying, since the latter results in distortion effects of knots. If a log is fully dried, the algorithm assumes that the heartwood goes all the way out to the surface of the log, but knot shapes are retained and the contrast between knots and clear wood is high.

For the knot height and knot end position, the results for the RH group is somewhat better than in Johansson et al. (2013), while the IH group performance is similar to Johansson et al. (2013). The overall improvement could be due to the higher longitudinal resolution in our data, compared to Johansson et al. (2013), $1 \mathrm{~mm}$ per slice compared to $10 \mathrm{~mm}$ per slice. The rotational position accuracy is a bit worse in this study than in Johansson et al. (2013), for both log groups, but this could be related to the fact that the logs from this study were partially dried. Nonetheless, detection of all these features was somewhat similar to those reported by Johansson et al. (2013), which demonstrates that the knot detection algorithm method developed for Scots pine and Norway spruce could be adapted for other wood species such as jack pine and white spruce.

The plots in Figure 4 show the detection of knot diameter and knot end in more detail. There was a large group of knots where the distance from pith to knot end was underestimated, i.e. the detection algorithm estimated the knot to be occluded while in reality it continued all the 
way out to the surface of the log. In this material, very few occluded knots were observed since the trees were only 32 years old at the time of harvest. As discussed in Johansson et al. (2013), this error is due to the low contrast between knots and sapwood.

The difference between the two species, with a larger detection rate for jack pine compared to white spruce, could have several explanations that were not investigated in detail. Knots in pine trees are usually larger but less numerous than in spruce trees, facilitating better detection. The average diameter of the largest branch in each tree, for the jack pine and white spruce trees used in this study, were 33.9 and $30.5 \mathrm{~mm}$, respectively. Also, Duchateau et al. (2013) found larger knot sizes in jack pine than in black spruce (Picea Mariana Mill.). Even though the spruce species was different in their study, it indicates a difference in knot size between pine and spruce that could be a reason for different detection rates. Furthermore, Bucur (2003) has reported that knot density is twice the average density of the surrounding wood when scanning a southern pine board. In Scots pine and Norway spruce, Boutelje (1966) has reported that wood density of knots was respectively $0.925 \mathrm{~g} / \mathrm{cm}^{3}$ and $1.01 \mathrm{~g} / \mathrm{cm}^{3}$ on average, while that of wood around knots was similar for both species $\left(\sim 0.66 \mathrm{~g} / \mathrm{cm}^{3}\right)$. Even though these wood species differ from those of this study, it can be hypothesized that size and quantity of knots could have a larger impact on detection rate than knot density in partially dried logs. Another factor could be the size of logs, since larger logs mean larger regions in which to search for knots. The average DBH for the jack pine trees of this study was $17.2 \mathrm{~cm}$, whereas the average DBH for the white spruce trees was $17.0 \mathrm{~cm}$. Also, the average volume of all the harvested jack pine trees was $238.7 \mathrm{dm}^{3}$, while the average volume of the white spruce trees was $175.4 \mathrm{dm}^{3}$ (Belley 2014).

The results indicate that it could be beneficial to measure and classify the detection of the sapwood-heartwood border in logs when using CT scanners in sawmills. Furthermore, they show that a proper management of the log yard with respect to moisture content is important 
for obtaining good scanning results. Logs that are partially dried out and therefore might fall in the IH group of this study, need to be handled with this in mind. Since the optimization results based on CT knot detection cannot be fully trusted, sawing of these logs could be optimized using only their outer shape, ignoring internal quality. When scanning logs for research purposes, the same is true as for the sawmills. If possible, only logs with a regular

252 heartwood shape should be used in databases of knots from CT scanned logs, if the results of the studied knot detection algorithm were used. This does not mean that the CT data from the irregular heartwood group should be discarded, just that the results from the Johansson et al. knot detection algorithm can be kept or discarded based on heartwood irregularity.

It should be noted however that the logs in this study were rather small given their relatively young age, therefore making knot detection more difficult. For larger logs, the problems with dried out areas of the sapwood might be smaller.

It can be concluded that knot detection using the algorithm developed by Johansson et al. (2013), performs worse in logs of jack pine and white sprucewhen the sapwood-heartwood border is irregular or detected poorly. It is however possible to group logs based on irregularity of the heartwood shape, in order to obtain one group with a relatively high detection rate.

\section{Acknowledgements}

The authors are grateful to the New Brunswick Department of Natural Resources for granting permission to sample trees in their Nelder plot, and to the Natural Sciences and Engineering Research Council of Canada (NSERC) for the financial support for CT data acquisition through the ForValueNet Strategic Research Network on Forest Management for Value-added Products. We are also thankful to Dr. Erik Johansson for his help with the knot detection algorithm, and to Professor Stavros Avramidis at UBC for facilitating the research done. 


\section{References}

Andreu, J.P., and Rinnhofer, A. 2003. Modeling of internal defects in logs for value optimization based on industrial CT scanning. In Fifth International Conference on Image Processing and Scanning of Wood, Bad Waltersdorf, Austria, 23-26 March 2003. Edited by Alfred Rinnhofer. pp. 23-26.

Baumgartner, R., Brüchert, F., and Sauter, U.H. 2010. Knots in CT scans of Scots pine logs. In The Future of Quality Control for Wood \& Wood Products, The Final Conference of COST Action E53, Edinburgh, United Kingdom, 4-7 May 2010. Edited by Dan Ridley-Ellis and John Moore. pp. 343-351.

Belley, D. 2014. Évaluation du volume et des pertes de qualité causées par les principaux défauts des tiges d'épinette blanche et de pin gris. Doctoral thesis, Université Laval, Québec, Canada.

Belley, D., Duchesne, I., Beaudoin, M., Vallerand, S., Tong, Q.J., and Swift, D.E. 2013. Assessment of white spruce and jack pine stem curvature from a Nelder spacing experiment. Wood Fiber Sci. 45(3): 237-249.

Berglund, A., Broman, O., Grönlund, A., and Fredriksson, M. 2013. Improved log rotation using information from a computed tomography scanner. Computers and Electronics in Agriculture. 90: 152-158. doi:10.1016/j.compag.2012.09.012.

Bhandarkar, S.M., Faust, T.D., and Tang, M. 1999. CATALOG: a system for detection and rendering of internal log defects using computer tomography. Machine Vision and Applications. 11(4): 171-190. doi:10.1007/s001380050100.

Boutelje, J.B. 1966. On the anatomical structure, moisture content, density, shrinkage, and resin content of the wood in and around knots in Swedish pine (Pinus Silvestris L.) and in Swedish spruce (Picea Abies Karst.). Svensk Papperstidning. 69(1): 1-10. 
Bucur, V. 2003. Nondestructive characterization and imaging of wood. Springer series in wood science. Springer. New York, USA.

Colquhoun, D. 2014. An investigation of the false discovery rate and the misinterpretation of p-values. Open Sci. 1(3). doi: 10.1098/rsos.140216.

Defo, M., and Brunette, G. 2006. A log drying model and its application to the simulation of the impact of bark loss. For. Prod. J. 56(5): 71.

Droessler, T., Bowyer, J.L., Burk, T., Jamrock, E., and Antilla, R. 1986. Rate of weight loss in piled pulpwood. Bulletin AD-Sb-3036. Agricultural Experiment Station, University of Minnesota, St. Paul, MN.

Duchateau, E., Longuetaud, F., Mothe, F., Ung, C., Auty, D., and Achim, A. 2013. Modelling knot morphology as a function of external tree and branch attributes. Can. J. For. Res. 43(3): 266-277. doi:10.1139/cjfr-2012-0365.

Guidiceandrea, F., Ursella, E., and Vicario, E. 2011. A high speed CT scanner for the sawmill industry. In Proceedings of the 17th International Nondestructive Testing and Evaluation of Wood Symposium, Sopron, Hungary, 14-16 September 2011. Edited by Ferenc Divos.

Johansson, E., Johansson, D., Skog, J., and Fredriksson, M. 2013. Automated knot detection for high speed computed tomography on Pinus sylvestris L. and Picea abies (L.) Karst. using ellipse fitting in concentric surfaces. Computers and Electronics in Agriculture. 96: 238-245. doi:10.1016/j.compag.2013.06.003

Krähenbühl, A., Kerautret, B., Debled-Rennesson, I., Mothe, F., and Longuetaud, F. 2014. Knot segmentation in 3D CT images of wet wood. Pattern Recognition. 47(12):3852-3869. doi: 10.1016/j.patcog.2014.05.015.Lindgren, L.O. 1991. Medical CAT-scanning: X-ray 
absorption coefficients, CT-numbers and their relation to wood density. Wood Sci. Technol. 25(5): 341-349. doi:10.1007/bf00226173.

Longuetaud, F., Leban, J.M., Mothe, F., Kerrien, E., and Berger, M.O. 2004. Automatic detection of pith on CT images of spruce logs. Computers and Electronics in Agriculture. 44(2): 107-119. doi:10.1016/j.compag.2004.03.005.

Longuetaud, F., Mothe, F., and Leban, J.M. 2007. Automatic detection of the heartwood/sapwood boundary within Norway spruce (Picea abies (L.) Karst.) logs by means of CT images. Computers and Electronics in Agriculture. 58(2): 100-111. doi:10.1016/j.compag.2007.03.010.

Longuetaud, F., Mothe, F., Kerautret, B., Krähenbühl, A., Hory, L., Leban, J.M., and DebledRennesson, I. 2012. Automatic knot detection and measurements from X-ray CT images of wood: a review and validation of an improved algorithm on softwood samples. Computers and Electronics in Agriculture. 85: 77-89. doi:10.1016/j.compag.2012.03.013.

Lundahl, C.G., and Grönlund, A. 2010. Increased yield in sawmills by applying alternate rotation and lateral positioning. For. Prod. J. 60: 331-338. doi:10.13073/0015-7473-60.4.331. Nelder, J.A. 1962. New kinds of systematic designs for spacing experiments. Biometrics 18: 283-307. doi:10.2307/2527473.

Oja, J., and Temnerud, E. 1999. The appearance of resin pockets in CT-images of Norway spruce (Picea abies (L.) Karst.). Holz als Roh-und Werkstoff. 57(5): 400-406. doi:10.1007/s001070050368.

Pietikäinen, M. 1996. Detection of knots in logs using x-ray imaging. Doctoral thesis, VTT Technical Research Centre of Finland, Oulu, Finland. 
Rinnhofer, A., Petutschnigg, A., and Andreu, J.P. 2003. Internal log scanning for optimizing breakdown. Computers and Electronics in Agriculture. 41: 7-21. doi:10.1016/s01681699(03)00039-5.

Roussel, J.R., Mothe, F., Krähenbühl, A., Kerautret, B., Debled-Rennesson, I., and Longuetaud, F. 2014. Automatic knot segmentation in CT images of wet softwood logs using a tangential approach. Computers and Electronics in Agriculture. 104: 46-56. doi: 10.1016/j.compag.2014.03.004.

Schmoldt, D.L., Li, P., and Abbott, A.L. 1996. A new approach to automated labeling of internal features of hardwood logs using CT images. In Review of Progress in Quantitative Nondestructive Evaluation. Edited by D.O. Thompson and D.E. Chimenti. Springer US. pp. 1883-1890. doi:10.1007/978-1-4613-0383-1_246.

Stängle, S.M., Brüchert, F., Heikkila, A., Usenius, T., Usenius, A., and Sauter, U.H. 2015. Potentially increased sawmill yield from hardwoods using X-ray computed tomography for knot detection. Annals of forest science. 72(1): 57-65. doi: 10.1007/s13595-014-0385-1.

Tong, Q., Duchesne, I., Belley, D., Beaudoin, M., and Swift, E. 2013. Characterization of knots in plantation white spruce. Wood Fiber Sci. 45(1): 84-97.

Wehrhausen, M., Laudon, N., Brüchert, F., and Sauter, U.H. 2012. Crack detection in computer tomographic scans of softwood tree discs. For. Prod. J. 62(6) :434-442. doi:10.13073/fpj-d-12-00079.1. 
Table 1. Range of tree features for the trees from which the chosen logs were taken in this study.

$\begin{array}{lll}\mathrm{DBH}^{\mathrm{a}}(\mathrm{cm}) & \begin{array}{l}\text { Maximum branch } \\ \text { diameter }(\mathrm{mm})\end{array} & \begin{array}{l}\text { Green crown height } \\ (\mathrm{m})\end{array}\end{array}$

Average

17

26

2.9

Minimum

10

13

0.8

Maximum

26

40

5.8

${ }^{\mathrm{a}}$ Diameter at breast height 
Table 2. Knot detection rates and amount of false positives, for all logs and separated by species and heartwood shape regularity as measured by the standard deviation of the sapwood thickness. Also, the results for all logs regardless of grouping is presented.

Jack pine White spruce All

\begin{tabular}{lllllll}
\hline $\begin{array}{l}\text { Detection } \\
\text { rate }\end{array}$ & $\begin{array}{l}\text { False } \\
\text { positives }\end{array}$ & $\begin{array}{l}\text { Detection } \\
\text { rate }\end{array}$ & $\begin{array}{l}\text { False } \\
\text { positives }\end{array}$ & $\begin{array}{l}\text { Detection } \\
\text { rate }\end{array}$ & $\begin{array}{l}\text { False } \\
\text { positives }\end{array}$ & $\begin{array}{l}\text { Number } \\
\text { of } \\
\text { detected } \\
\text { knots }\end{array}$
\end{tabular}

\begin{tabular}{lccccccc}
\cline { 2 - 7 } RH group & $87.3 \%$ & $1.9 \%$ & $71.2 \%$ & $4.9 \%$ & $79.0 \%$ & $3.5 \%$ & 937 \\
IH group & $69.0 \%$ & $4.5 \%$ & $47.2 \%$ & $7.5 \%$ & $56.0 \%$ & $5.0 \%$ & 796 \\
$\begin{array}{l}\text { Both } \\
\text { groups }\end{array}$ & $79.6 \%$ & $2.9 \%$ & $59.3 \%$ & $6.0 \%$ & $68.4 \%$ & $4.7 \%$ & 1733 \\
\hline
\end{tabular}


Table 3. Detection accuracy of knot diameter, position and end point for all logs.

\begin{tabular}{|c|c|c|c|c|c|c|}
\hline $\begin{array}{l}\text { Heartwood } \\
\text { shape } \\
\text { group }\end{array}$ & Knot feature & Mean error & $\mathrm{SD}^{\mathrm{a}}$ & $\mathrm{RMSE}^{\mathrm{b}}$ & $\mathrm{R}^{2, \mathrm{c}}$ & $\begin{array}{l}\text { Sample } \\
\text { size }\end{array}$ \\
\hline RH & Dia $(0,10)(\mathrm{mm})$ & -0.178 & 2.68 & 2.68 & 0.24 & 2807 \\
\hline RH & Dia $[10,20)(\mathrm{mm})$ & -3.44 & 5.03 & 6.09 & 0.072 & 2221 \\
\hline $\mathrm{RH}$ & Dia $[20, \infty)(\mathrm{mm})$ & -6.49 & 10.6 & 12.4 & 0.00 & 266 \\
\hline RH & Dia total (mm) & -1.87 & 4.87 & 5.21 & 0.36 & 5294 \\
\hline $\mathrm{RH}$ & Height position (mm) & -1.16 & 7.03 & 7.13 & - & 5258 \\
\hline $\mathrm{RH}$ & Rotational position $\left(^{\circ}\right)$ & -0.206 & 5.06 & 5.07 & - & 5258 \\
\hline $\mathrm{RH}$ & Knot end ${ }^{\mathrm{d}}(\mathrm{mm})$ & -6.62 & 18.1 & 19.3 & 0.15 & 937 \\
\hline $\mathrm{IH}$ & Dia $(0,10)(\mathrm{mm})$ & -0.483 & 2.73 & 2.78 & 0.16 & 1511 \\
\hline $\mathrm{IH}$ & Dia $[10,20)(\mathrm{mm})$ & -5.26 & 5.68 & 7.74 & 0.014 & 1203 \\
\hline $\mathrm{IH}$ & $\operatorname{Dia}[20, \infty)(\mathrm{mm})$ & -10.3 & 10.4 & 14.6 & 0.0024 & 302 \\
\hline $\mathrm{IH}$ & Dia total (mm) & -3.37 & 6.15 & 7.01 & 0.21 & 3016 \\
\hline $\mathrm{IH}$ & Height position (mm) & -2.81 & 9.74 & 10.1 & - & 3011 \\
\hline $\mathrm{IH}$ & Rotational position $\left(^{\circ}\right)$ & 0.0199 & 6.25 & 6.25 & - & 3011 \\
\hline $\mathrm{IH}$ & Knot end (mm) & -11.7 & 24.3 & 26.90 & 0.10 & 796 \\
\hline
\end{tabular}

${ }^{\mathrm{a}}$ standard deviation of detection error

${ }^{\mathrm{b}}$ Root Mean Square Error

${ }^{\mathrm{c}}$ Coefficient of determination

${ }^{\mathrm{d}}$ radial distance from pith to knot end, i.e. a straight line

Note: Data is sorted by heartwood shape group (RH or IH) and knot diameter class (small, medium, and big). 
Figures

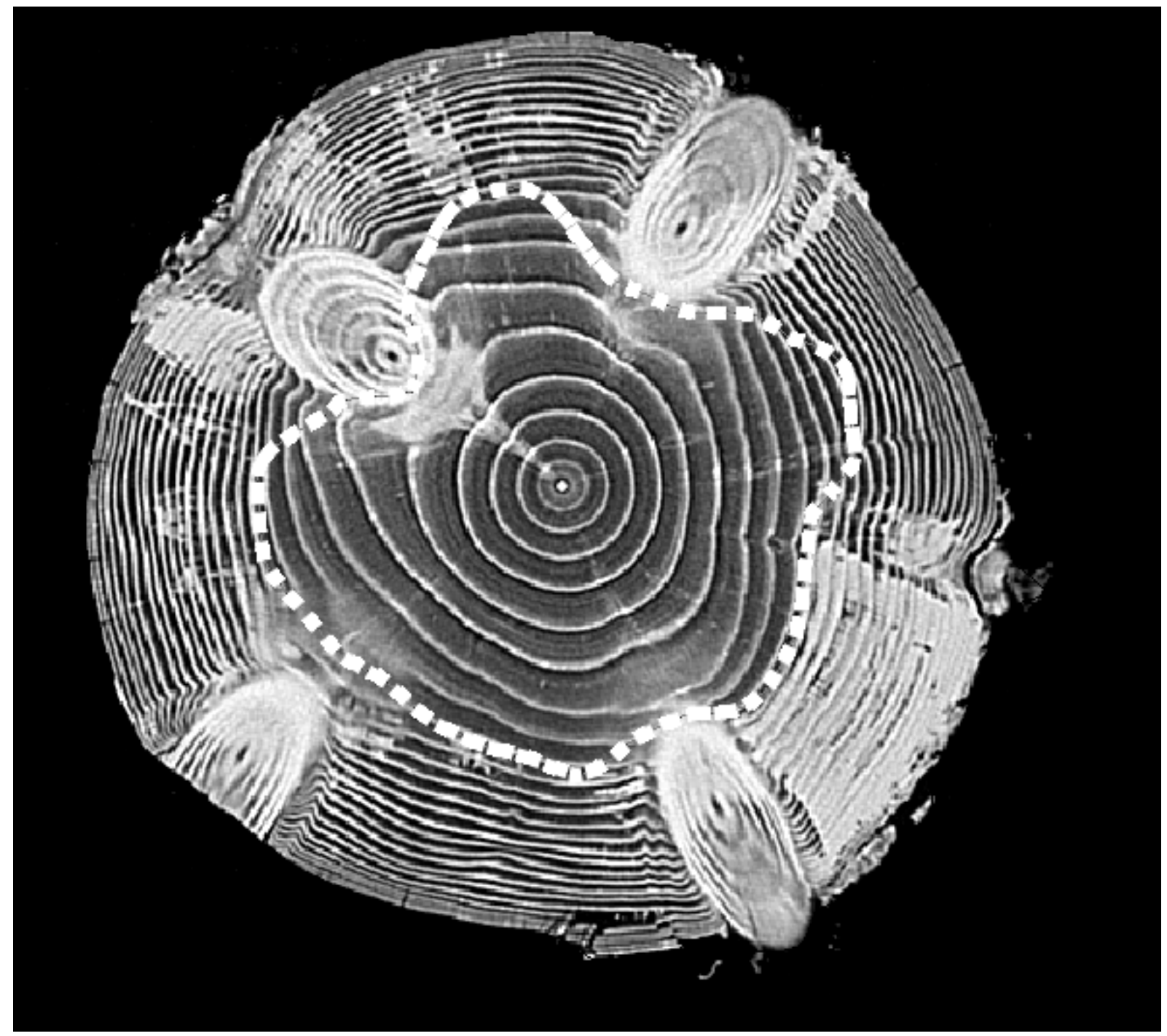

Figure 1 


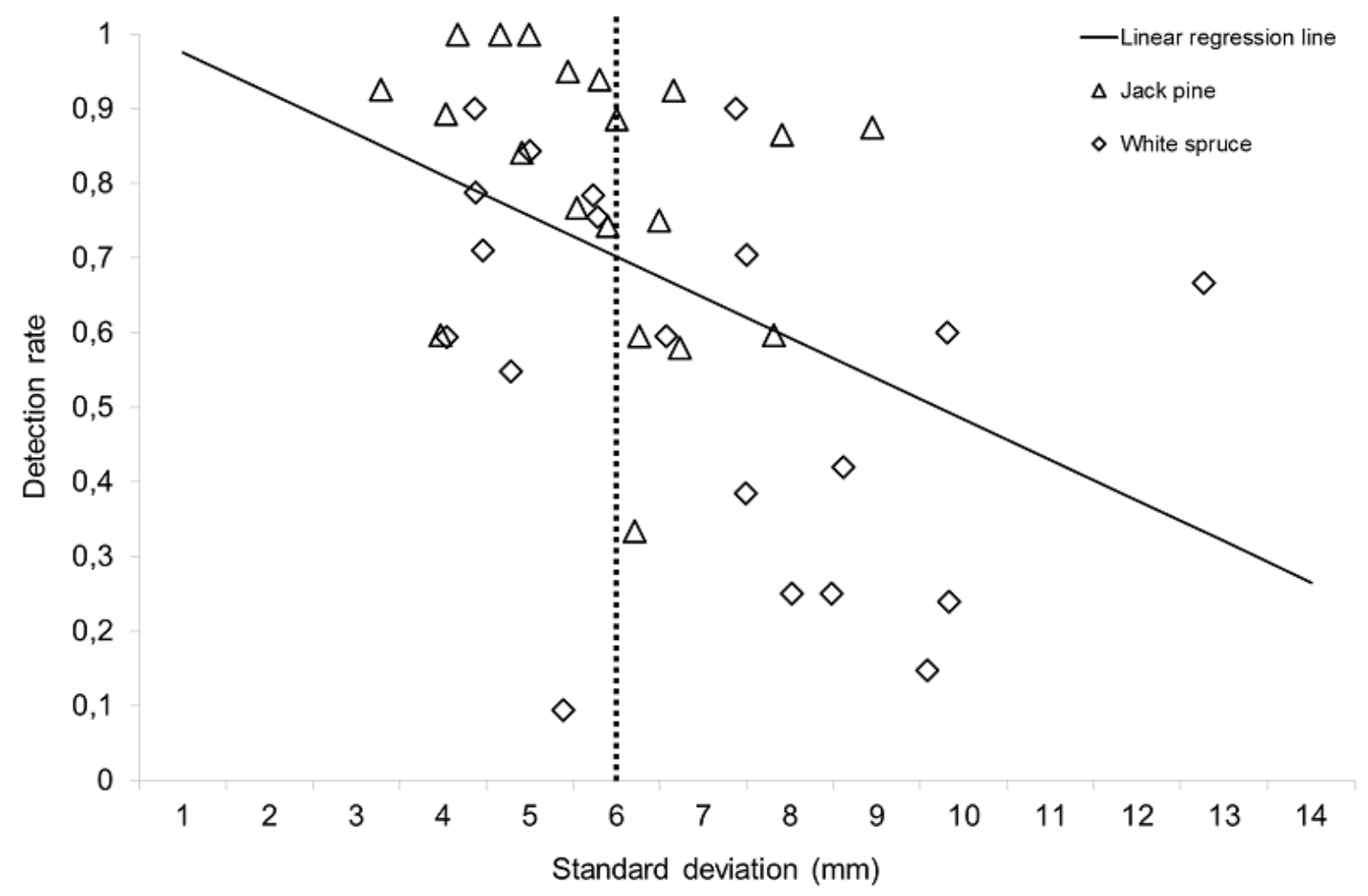

Figure 2 


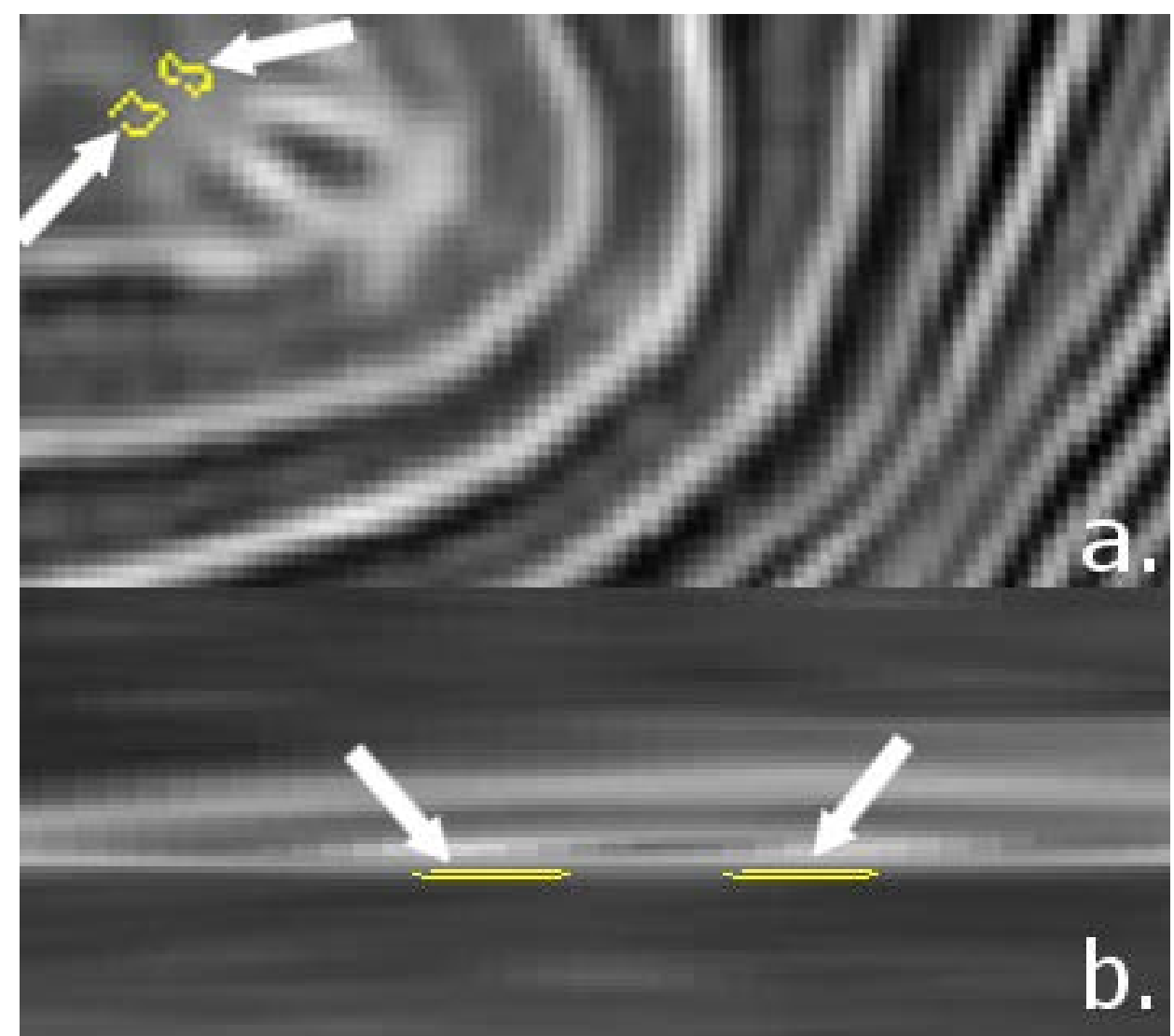

Figure 3 
a)

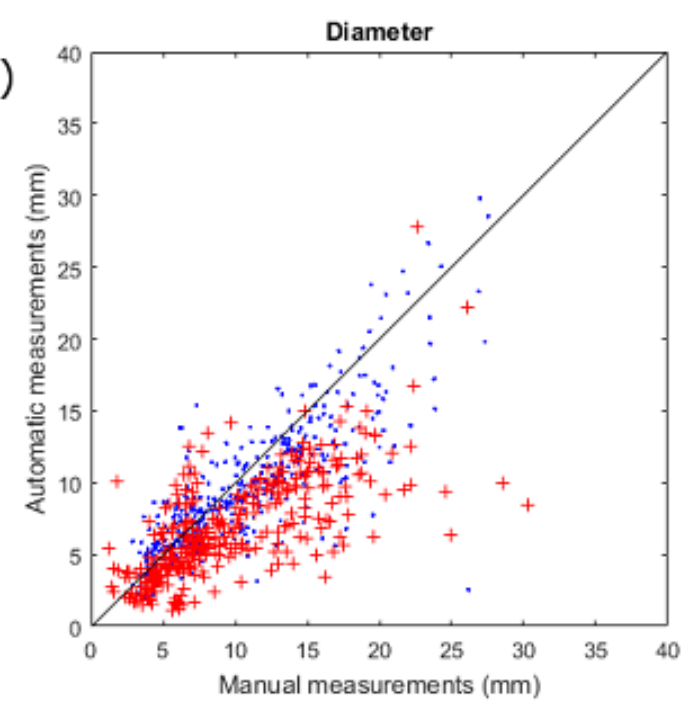

c)

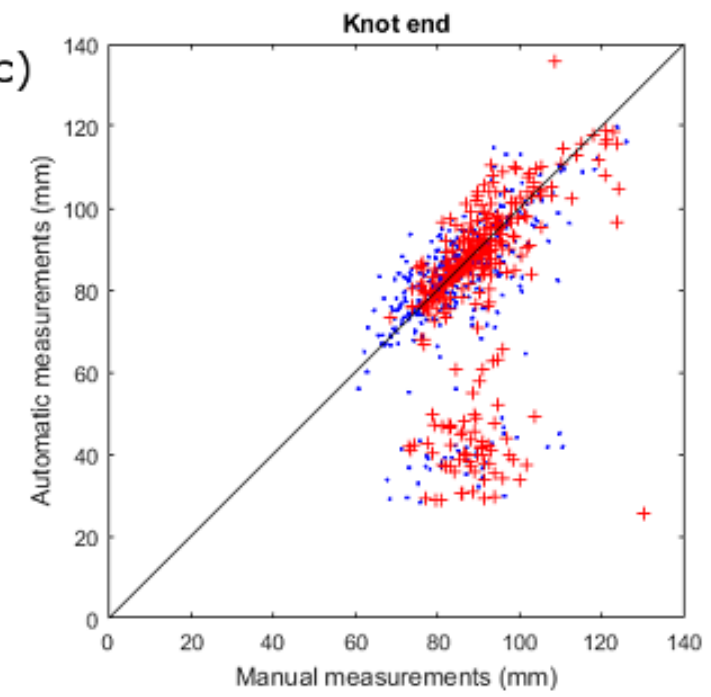

b)

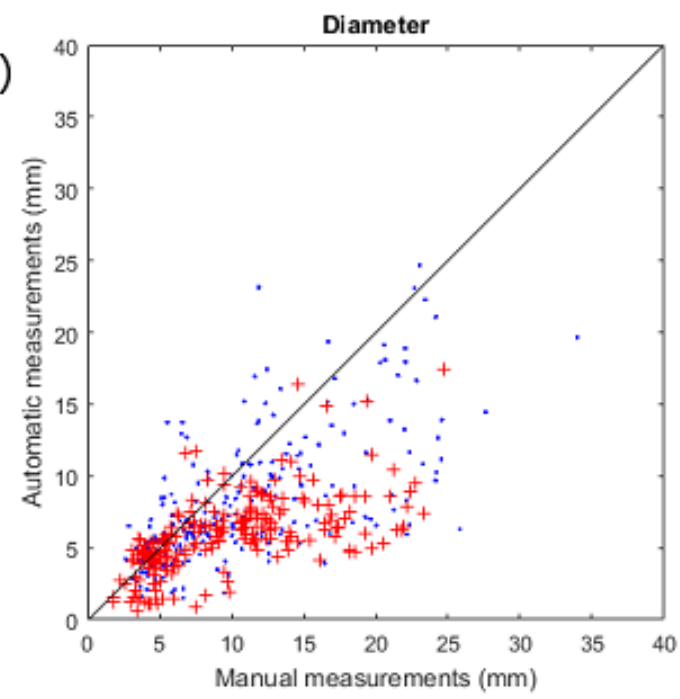

d)

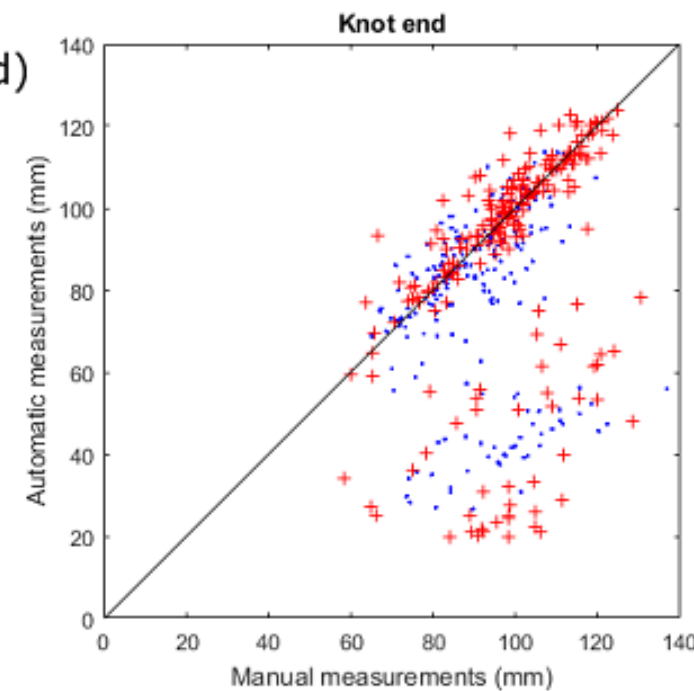

Figure 4 


\section{Figure captions}

Figure 1. Cross section of CT scanned jack pine log, with parts of the sapwood dried out (i.e. low density dark zones in the outer rings), and parts still having high moisture content (i.e. high density white zones in the outer rings). The dashed bright line shows the heartwoodsapwood border detected by the Baumgartner et al. (2010) algorithm. If the dry pocket borders the heartwood-sapwood border, it is difficult to tell the difference between the two types of wood since they have almost the same density. Also, the detection result is affected by the presence of large knots.

Figure 2. Knot detection rate plotted against standard deviation of sapwood thickness, for all logs of the study. A linear regression line fitted to the data is included as well, with a coefficient of determination $\left(\mathrm{R}^{2}\right)$ of 0.19 . The vertical dashed line indicates where the cut-off was made between regular and irregular heartwood groups.

Figure 3. An example of a "false positive" that is in fact a knot that has been detected as two, due to the low density region in the center of the knot. Figure 3a shows the knot viewed in a CT cross-section, while Figure 3b shows the same knot in a concentric surface, as an ellipsoid shape. The bright marks, indicated by arrows, show two knots according to the detection algorithm. The wood species is white spruce.

Figure 4. Scatter plots for the RH and IH groups showing automatic and manual measurements of knot size and knot end point. Measurements from jack pine are represented by points, measurements from white spruce by plus signs. An identity line is included as reference. 4a: RH group, average knot diameter. Each point represents the average of all diameter measurements from one knot. 4b: IH group, average knot diameter. Each point represents the average of all diameter measurements from one knot. 4c: RH group, knot end. Each point represents one knot. 4d: IH group, knot end. Each point represents one knot. The values in $4 \mathrm{c}$ and $4 \mathrm{~d}$ were calculated as the shortest radial distance from the pith to the knot end. 